\title{
Effect of interactive distraction versus cutaneous stimulation for venipuncture pain relief in school age children
}

\author{
Sahar Mahmoud El-Khedr Abd El-Gawad *1,2, Lamiaa Ahmed Elsayed ${ }^{2,3}$ \\ ${ }^{1}$ Faculty of Nursing, Tanta University, Tanta, Egypt \\ ${ }^{2}$ Faculty of Nursing, Umm Al Qura University, Makkah Al- Mukarramah, Kingdom of Saudi Arabia \\ ${ }^{3}$ Pediatric Nursing, Faculty of Nursing, Ain shams University, Egypt
}

Received: October 30, 2014

DOI: $10.5430 /$ jnep.v5n4p32
Accepted: January 14, 2015 Online Published: January 21, 2015

URL: http://dx.doi.org/10.5430/jnep.v5n4p32

\begin{abstract}
Introduction: Venipuncture in pediatrics is one of the most distressing events and the most routinely performed invasive procedures that the child may expose during his/her hospitalization or illness. Non-pharmacological techniques are used to reduce venipuncture related pain. Distraction is a non-pharmacological technique that draws attention of the child away from the pain. Cutaneous stimulation is an independent nursing intervention that advocated relieving pain. This study aims to examine the effectiveness of the interactive distraction versus cutaneous stimulation for venipuncture pain relief in school age children.

Method: Design: Quasi experimental study was used. Setting: the study was conducted at Children Hospital that is affiliated to Ain Shams University Hospitals. Data was collected from Emergency and Pediatric Medical Ward. Sampling: purposive samples of 100 children were involved in this study they were divided into 2 equal groups, 50 children in each group. Tools of data collection, Tool 1: questionnaire sheet, Tool 2: Pain assessment tool, Tool 3: monitoring vital signs and oxygen saturation were done 15 minutes before vein-puncture and 15 minutes after vein-puncture.

Results: The results revealed statistical significance difference between cutaneous stimulation and interactive distraction group.

Conclusion: The present study concludes that; interactive distraction technique had a positive pain relive effect and was better than cutaneous stimulation in relieving children's pain during vein-puncture. There is significant difference between the effect of cutaneous stimulation and distraction techniques on children's pain during vein-puncture. Recommendations: Application of non-pharmacological pain management in hospitals as a routine care, and further studies needed to evaluate the effectiveness of other non-pharmacological management techniques.
\end{abstract}

Key Words: Non-pharmacological management, Interactive distraction, Cutaneous stimulation, Vein puncture \& pain management

\section{Introduction}

Pain is defined as, whatever the experiencing person says it is, existing whenever the experiencing person says it does. ${ }^{[1]}$
The International Association for the Study of Pain has a definition that is widely used: Pain is an unpleasant sensory and emotional experience associated with actual or potential tissue damage, or described in terms of such damage. Pain

\footnotetext{
*Correspondence: Sahar Mahmoud El-Khedr Abd El-Gawad; Email: sahar.khedr@yahoo.com; Address: Faculty of Nursing, Tanta University, Tanta, Egypt.
} 
can interfere with recovery from surgery or illness, prevent normal activity and affect a child's quality of life. The definition implies the attitude of children toward pain using both verbal and nonverbal expression. ${ }^{[2]}$

The American pain society created the phrase "pain: as the fifth vital signs" to increase awareness of pain assessment among health care professionals especially nurses. ${ }^{[3]}$ The rational is that if pain were assessed seriousness as other vital signs, it would more likely to be treated properly. The principle of pain assessment is to assess patients for pain every time the nurses must checks for pulse, blood pressure, temperature, and respiratory rate. ${ }^{[4]}$

Children in school age group relate to pain physically by its location in terms of body parts. They are afraid their bodies will be damaged so, they require more practice with relaxation techniques than do younger children. Children may often feel a lot of guilt and display different behaviors when they are in pain. They are beginning to develop a sense of cause and effect and can understand that the pain is likely due to some injury or illness. They may also understand that being in the hospital and undergoing painful procedures will help them feel better. ${ }^{[4,5]}$

Vein-punctures is a medical term used to describe the act of puncturing a vein, whether to draw blood or to insert an intravenous injection, or IV, catheter. Vein-punctures can be performed using butterfly needles, or a simple needle attached to a blood collection tube. Performing veinpunctures successfully takes hands-on practice, and practitioners should follow the vein-punctures guidelines to ensure that proper policies and procedures are maintained Venipuncture in pediatrics can be one of the most distressing events and the most routinely performed invasive procedures that the child may expose during his/her hospitalization or illness. ${ }^{[6]}$ The role of pediatric nurses includes helping children through such procedures. The nurse caring for a child during a procedure through helping the child effectively, and ensuring that the procedure is done as efficiently as possible. ${ }^{[7]}$

Children may be less able than an adult to articulate their experience or needs related to pain, which may result in under treatment of pain. There is a relationship between stress and the immune system. If stress hormones are chronically elevated, this hormone will destroy the healthy immune cells that fight viruses and tumors and keep the immune system healthy. Relief of pain is a basic need and right of all children, effective pain management requires that health professional including nurses, be willing to try a number of interventions to achieve optimal results. Basically, pain-reducing methods can be grouped into two categories: non-pharmacologic and pharmacologic. Whenever possible, both should be used; however, non-pharmacologic measures are substitutes for analgesics. ${ }^{[1]}$
Non-pharmacological techniques is used to reduce venipuncture related pain and reduce drug side effects that can be performed independently by nurses. A number of non-pharmacological techniques, such as distraction, relaxation, guided imagery, and cutaneous stimulation provide coping strategies that may help reduce pain perception, decrease anxiety. ${ }^{[8]}$

Non pharmacological pain management consists of a variety of physical, cognitive-behavioral, and lifestyle pain management strategies that target the body, mind, spirit, and social interactions. ${ }^{[5,6]}$ Non-pharmacological pain management especially massage and distraction techniques may be applied to children. ${ }^{[6]}$ Distraction draws attention or engaging a child in a wide variety of pleasant activities away from the pain. This helps children to focus attention on something other than pain and the anxiety to lessens the perception of pain. In some instances, distraction can make a child completely unaware of pain and time to the extent that the distracting activity holds his or her "undivided" attention especially during vein puncture. ${ }^{[4]}$ Distraction activities are listening to music, singing a song, blowing bubbles, playing a game, watching television or a video, and focusing on a picture while counting. Guided imagery and breathing techniques. ${ }^{[9]}$

Cutaneous stimulation is defined as stimulation of the skin and underlying tissues for the purpose of decreasing undesirable signs and symptoms such as pain, muscle spasm or inflammation. It also referred to as peripheral technique; describe any form of stimulation of the skin with the goal of pain relief. Cutaneous stimulation is performed by several methods such as simple rhythmic rubbing, use of pressure or electric vibrators, massage with hand and application of heat or cold at the site before injection. Touching competes with the pain stimuli that are transmitted from the peripheral nerves to the spinal cord and brain and may reduce the pain felt by the child. ${ }^{[10]}$ Research evidence show that cutaneous stimulation is an independent nursing intervention that advocated relieving pain and the nurse in practice is qualified to give it accurately. ${ }^{[11,12]}$

\subsection{Significance of the study}

Pain is a stressful experience that is considered to be a global health problem, and children are vulnerable and under-served population. Despite the exponential increase in scientific evidence about pediatric pain in the last few decades, there are many barriers to the transfer of knowledge to clinical practice. Consequently, children still experience unnecessary pain during hospitalization. ${ }^{[13-15]}$ Nonpharmacological techniques are effective methods for pain relive. Pain can be managed especially during painful procedures if the nurse makes appropriate assessment and intervention. Instead of the international and hospitals' recommendations in the use of pain assessment tool routinely with vital signs, nurses didn't use pain assessment scale or 
non-pharmacological methods in the care of pediatric children. Non-pharmacological strategies are inexpensive, easy to provide and safe. There are very few studies to evaluate the effectiveness of non-pharmacological techniques in reducing children's pain. Millions of children experience these common painful procedures like vein-puncture which cause considerable distress. ${ }^{[16-18]}$

\subsection{Aim of the study}

This study aims to examine the effectiveness of the interactive distraction versus cutaneous stimulation for venipuncture pain relief in school age children.

\section{Hypothesis}

- Both interactive distraction and cutaneous stimulation relieve children's pain during vein-puncture.

- There is no difference between interactive distraction and cutaneous stimulation in relieving children's pain during vein-puncture.

\section{Subjects and methods}

\subsection{Design}

A Quasi experimental study was used in the current study.

\subsection{Setting}

The study was conducted at Children Hospital affiliated to Ain Shams University Hospitals. Data was collected from Emergency Ward and Medical Ward.

\subsection{Sampling}

Purposive sample of 100 children was involved in this study. It was classified into 2 equal groups, 50 children in each group. The researchers assigned the first 50 children to interactive distraction group and the second 50 children were assigned to cutaneous stimulation group. The two procedures were carried out during vein-puncture.

\subsection{Inclusion criteria}

- Age: 6-12 years.

- Free from chronic and, persistent pain.

- Free from any psychological, mental or communication problems.

\subsection{Tools}

Three tools were used in this study for data collection.

\section{Tool I : Questionnaire sheet}

It was classified into 2 parts:

Part 1 : Children demographic data: include "Child's name, age, sex, birth order and level of education(class)".
Part 2: Child' medical history, history of pain, which included "present - past history", history and reason of previous admission, previous exposure to pain and number of previous vein puncture during hospitalization.

\section{Tool II: Pain assessment tool}

It was classified into 2 parts:

Part 1: Wong-baker faces pain rating scale: The scale consists of six cartoon faces ranging from smiling face for "no pain" to tearful face for "worst pain". [1] When using the faces, each child select the face that corresponded to his feeling of pain. The scale was ranged from 0-5, happy face scored zero because there is no pain or hurt, to a sad face scored 5 because there is some or a lot of pain. This rating scale recommended for children older than 3 years. ${ }^{[2]}$

Part 2: Visual Analogue Scale: Visual analogue scales consist of a $10 \mathrm{~cm}$ line ranged from $0-10$. Labeled "No Hurt" scored zero on the left and "Worst Hurt" that scored 10 on the right. Children are asked to indicate their pain intensity by putting a mark on the scale that corresponds to their pain intensity. Visual analogue scales are designed to assess the intensity of pain only. Once the scale is explained to the child, he is asked to point to the place on the line that best represents how much pain he is feeling.

\section{Tool III}

Monitoring vital signs and oxygen saturation were done 15 minutes before vein-puncture and 15 minutes after veinpuncture. Using electronic vital signs monitor and pulse oximeter.

\subsection{Data collection}

Simple explanation to the children and their mothers was done. Those who agreed to participate were involved in this study. The children were classified into two groups the interactive distraction and cutaneous stimulation group.

\subsection{Methods}

The Questionnaire sheet was developed by researchers. The tools were examined, revised and the appropriate modifications were done. The second tool, pain assessment tools (part 1\&2), retrieved from Berman, (2008). The third tool was developed by the researchers.

The researchers collected data at a period of four months from the beginning of June to the end of September (2013) The researchers were available three days per week. Demographic data, vital signs and $\mathrm{O}_{2}$ saturation were assessed at the beginning of the study. The researchers use the interactive distraction or cutaneous stimulation during veinpuncture, and assess pain using both Wong-baker faces pain rating scale and visual analogue pain scale. After veinpuncture vital signs and $\mathrm{O}_{2}$ saturation were assessed again. 
The researcher assess vital signs and $\mathrm{O}_{2}$ saturation using pulse oximeter 15 minutes Before vein-puncture then, cutaneous stimulation using massage techniques applied slowly to the hand and fingers a way from injection site 5 minutes before vein-puncture and continue for 5 minutes after the procedure. For the second group simple distraction techniques that divert or draw attention away from painful stimuli was used through using portable note video show. The children were asked about the preferred game or video and administered 5 minutes before the procedure and continue for 5 minutes after the procedure.

\subsection{Pilot study}

Prior to the actual study, a pilot study was conducted on $10 \%$ of the study sample ( 5 patients for each technique distraction and cutaneous stimulation) to test study tools for its clarity, feasibility , applicability and determine the required time to fulfill the tools and then necessary modifications was done. The pilot study was excluded from the research. The tools of data collection were tested for validity by giving the tools to five expertise in the field to review it. Reliability test using Cronbach's alpha was utilized to test the internal consistency of the tools, reliability was $(0.88)$ for Visual Analogue pain scale.

\subsection{Ethical consideration}

A formal approval was taken from the administrator of Ain Shams University Hospital and the head of the Emergency and Medical Wards. Simple explanation about the aim of the study was also done for the mothers and the children and those how accepted to participate were involved in the current study. During the work every effort was made to ensure the safety, privacy, and confidentiality for each child.

\subsection{Statistical analysis}

The collected data were organized, tabulated, computerized and analyzed using SPSS. ${ }^{[1]}$ Procedures used included the calculation of descriptive statistics and, where appropriate, the application of t-test, chi-squared tests and correlation tests between essential parameters in order to answer the research questions.

\section{Results}

As regards, Table 1 shows distribution of the study sample according to demographic data. It was evident that $50 \%$ of the cutaneous stimulation group aged between $6<8$ years while $30 \%$ and $20 \%$ aged from $8<10$ years and $10-12$ years respectively with a mean age of $8.52+1.5$ years. Twenty four percent of the interactive distraction group aged from $6<8$ years compared to $34 \%$ and $42 \%$ who aged from $8<10$ and 10-12 years respectively with a mean age of 8.03 +1.86 . Nearly equal percent of the cutaneous group and interactive group were males, $56 \%$ and $54 \%$ respectively.

Table 1: Percent distribution of the study sample according to their demographic data

\begin{tabular}{|c|c|c|c|c|}
\hline \multirow{2}{*}{ Items } & \multicolumn{2}{|c|}{ Cutaneous stimulation } & \multicolumn{2}{|c|}{ Interactive distraction } \\
\hline & n. $=50$ & $\%$ & n. $=\mathbf{5 0}$ & $\%$ \\
\hline \multicolumn{5}{|l|}{ Age in years } \\
\hline $6-8$ & 25 & 50 & 12 & 24 \\
\hline $8-10$ & 15 & 30 & 17 & 34 \\
\hline $10-12$ & 10 & 20 & 21 & 42 \\
\hline Mean \pm SD (age) & \multicolumn{2}{|c|}{$8.52 \pm 1.50$} & \multicolumn{2}{|c|}{$8.03 \pm 1.86$} \\
\hline \multicolumn{5}{|l|}{ Gender } \\
\hline Male & 28 & 56 & 27 & 54 \\
\hline Female & 22 & 44 & 23 & 46 \\
\hline
\end{tabular}

Distribution of the study sample according to medical history was illustrated in Table 2 . It was found that $60 \%$ of the cutaneous stimulation group previously admitted to the hospital compared to $48 \%$ of the interactive distraction group. Three quarters and $50 \%$ of the cutaneous stimulation and interactive distraction group respectively admitted because of medical problem. Exposure to painful procedure was expressed by $72 \%$ and $68 \%$ of the cutaneous stimulations and interactive distraction group respectively. One fifth of the cutaneous stimulation group $(20 \%)$ exposed to vein puncture once and two fifth (40\%) from 2-3 times, while $18 \%$ of the interactive distraction group exposed to vein puncture once compared to $38 \%$ of the same group who exposed to vein puncture $2-3$ times.

Children response according to Wong Baker Faces pain rating scale illustrated that $10 \% \& 28 \%$ of the cutaneous stimulation group had hurts little bit and hurts little more respectively, equal percent of $18 \%$ of the same group has hurts whole lot and hurts worst. Hurts little bit and hurts little more were expressed by $20 \%$ and $36 \%$ of the interactive distraction group respectively, while it was $18 \%$ hurts whole lot and $12 \%$ hurts worst. Statistical significant difference was found ( $P=.039$ ) (see Table 3). 
Table 2: Percent distribution of study sample according to their medical history

\begin{tabular}{|c|c|c|c|c|}
\hline \multirow{2}{*}{ Items } & \multicolumn{2}{|c|}{ Cutaneous stimulation } & \multicolumn{2}{|c|}{ Interactive distraction } \\
\hline & n. $=\mathbf{5 0}$ & $\%$ & n. $=\mathbf{5 0}$ & $\%$ \\
\hline \multicolumn{5}{|l|}{ Previous admission } \\
\hline Yes & 30 & 60 & 24 & 48 \\
\hline No & 20 & 40 & 26 & 52 \\
\hline \multicolumn{5}{|l|}{ Reason for admission } \\
\hline Medical problem & 18 & 75 & 12 & 50 \\
\hline Surgical problem & 4 & 16.7 & 6 & 25 \\
\hline Accident \& emergency & 2 & 8.3 & 6 & 25 \\
\hline \multicolumn{5}{|l|}{ Exposure to painful procedures } \\
\hline Yes & 36 & 72 & 34 & 68 \\
\hline No & 14 & 28 & 16 & 32 \\
\hline \multicolumn{5}{|l|}{ Previous vein-punctures } \\
\hline No exposure & 11 & 22 & 10 & 20 \\
\hline Once & 10 & 20 & 9 & 18 \\
\hline 2-3tims & 20 & 40 & 19 & 38 \\
\hline 4-5tims & 3 & 6 & 6 & 12 \\
\hline$>$ tims & 6 & 12 & 6 & 12 \\
\hline Mean \pm SD (exposure to vein puncture) & \multicolumn{2}{|c|}{$2.13 \pm 0.97$} & \multicolumn{2}{|c|}{$2.23 \pm 0.97$} \\
\hline
\end{tabular}

Table 3: Comparison between cutaneous stimulation group and interactive distraction group according to wong-baker faces pain rating scale during venipuncture

\begin{tabular}{|c|c|c|c|c|c|c|}
\hline \multirow{2}{*}{ Items } & \multicolumn{2}{|c|}{ Cutaneous stimulation } & \multicolumn{2}{|c|}{ Interactive distraction } & \multirow{2}{*}{$\chi^{2}$} & \multirow{2}{*}{$P$-value } \\
\hline & n. $=\mathbf{5 0}$ & $\%$ & n. $=\mathbf{5 0}$ & $\%$ & & \\
\hline Hurts Little Bit & 8 & 10 & 10 & 20 & & \\
\hline Hurts Little More & 14 & 28 & 18 & 36 & & \\
\hline Hurts Even More & 13 & 26 & 6 & 14 & 10.11 & $.039 *$ \\
\hline Hurts Whole Lot & 9 & 18 & 9 & 18 & & \\
\hline Hurts Worst & 6 & 18 & 7 & 12 & & \\
\hline
\end{tabular}

*Significant at $\leq .05$

Children expression of pain according to visual analogue scale was illustrated in Table 4. It was evident that $16 \%$ and $20 \%$ of the cutaneous stimulation group and interactive distraction group respectively was mentioned no pain. Mild pain expressed by $62 \%$ and $60 \%$ while moderate pain men- tioned by $18 \%$ and $20 \%$ of the cutaneous stimulation group and interactive distraction group respectively. Severe pain was expressed by $4 \%$ of the cutaneous stimulation group compared by none of the interactive distraction group. Statistical significant difference was found $(P=.000)$.

Table 4: Comparison between cutaneous stimulation group and interactive distraction group according to visual analogue scale during venipuncture

\begin{tabular}{|c|c|c|c|c|c|c|}
\hline \multirow{2}{*}{ Items } & \multicolumn{2}{|c|}{ Cutaneous stimulation } & \multicolumn{2}{|c|}{ Interactive distraction } & \multirow{2}{*}{$\chi^{2}$} & \multirow{2}{*}{$P$-value } \\
\hline & n. $=\mathbf{5 0}$ & $\%$ & n. $=\mathbf{5 0}$ & $\%$ & & \\
\hline No pain & 8 & 16 & 10 & 20 & \multirow{4}{*}{117.10} & \multirow{4}{*}{$.000^{*}$} \\
\hline Mild pain & 31 & 62 & 30 & 60 & & \\
\hline Moderate pain & 9 & 18 & 10 & 20 & & \\
\hline Severe pain & 2 & 4 & - & - & & \\
\hline
\end{tabular}

Table 5 shows difference between vital signs and $\mathrm{O}_{2}$ Saturation before and after cutaneous stimulation. it was clarified that the mean temperature before cutaneous stimulation was $37.03+.60$ and $36.98+.36$ after cutaneous stimulation. Regarding to pulse, it was found that statistical significance 36 difference before and after cutaneous stimulation $(P=.003)$. Statistical significance difference was found regarding Systolic blood pressure $(P=.043)$. The mean of $\mathrm{O}_{2}$ saturation was $96.30+2.67$ before cutaneous stimulation and $96.24+$ 2.42 after cutaneous stimulation.

ISSN 1925-4040 E-ISSN 1925-4059 
Table 5: Difference between vital signs and $\mathrm{O}_{2}$ saturation before and after cutaneous stimulation during venipuncture

\begin{tabular}{|c|c|c|c|c|c|c|}
\hline & \multicolumn{2}{|l|}{ Before } & \multicolumn{2}{|l|}{ After } & \multirow{2}{*}{$t$ test } & \multirow{2}{*}{$P$ value } \\
\hline & Mean & SD. & Mean & SD. & & \\
\hline Temperature & 37.03 & .60 & 36.98 & .36 & .833 & .409 \\
\hline Pulse & 100.42 & 30.07 & 90.12 & 18.31 & 3.103 & $.003^{*}$ \\
\hline Respiration & 30.72 & 11.56 & 28.36 & 5.24 & 1.638 & .108 \\
\hline Systolic blood pressure & 107.78 & 10.26 & 104.24 & 9.08 & 2.078 & $.043 *$ \\
\hline Diastolic blood pressure & 67.90 & 10.77 & 65.86 & 10.26 & 1.909 & .062 \\
\hline Oxygen Saturation & 96.30 & 2.67 & 96.24 & 2.42 & .312 & .757 \\
\hline
\end{tabular}

*Significant at $\leq .05$

The difference between Vital Signs and $\mathrm{O}_{2}$ Saturation before and after interactive distraction was illustrated in Table 6. It was clarified that the mean temperature before and after Interactive Distraction were $37.06+.47$ and $37.05+$ .52. Statistical significance difference was found regarding pulse and respiration before and after interactive distraction
$(P=.001)$ and $(P=.002)$ respectively. Statistical significance difference was found regarding Systolic blood pressure and Diastolic blood pressure $(P=.014)$ and $(P=.023)$ respectively. The mean of $\mathrm{O}_{2}$ saturation was $96.66+3.04$ before Interactive Distraction and $96.88+2.84$ after Interactive Distraction.

Table 6: Difference between vital signs and $\mathrm{O}_{2}$ saturation before and after interactive distraction during venipuncture

\begin{tabular}{|c|c|c|c|c|c|c|}
\hline \multirow{2}{*}{ Items } & \multicolumn{2}{|l|}{ Before } & \multicolumn{2}{|l|}{ After } & \multirow{2}{*}{$t$ test } & \multirow{2}{*}{$P$ value } \\
\hline & Mean & SD.S & Mean & SD.S & & \\
\hline Temperature & 37.06 & 0.47 & 37.05 & 0.52 & 0.140 & .889 \\
\hline Pulse & 89.44 & 18.70 & 98.98 & 26.05 & 3.391 & $.001 *$ \\
\hline Respiration & 29.84 & 4.79 & 28.20 & 2.42 & 1.010 & $.002 *$ \\
\hline Systolic blood pressure & 109.68 & 12.61 & 105.76 & 16.86 & 2.545 & $.014 *$ \\
\hline Diastolic blood pressure & 65.28 & 8.11 & 62.88 & 8.48 & 2.770 & $.023^{*}$ \\
\hline Oxygen Saturation. & 96.66 & 3.04 & 96.88 & 2.84 & 0.573 & .569 \\
\hline
\end{tabular}

*Significant at $\leq .05$

Table 7 shows a comparison between cutaneous stimulation group and interactive distraction group as regards vital signs and $\mathrm{O}_{2}$ Saturation after vein-puncture. This table clarified that the mean temperature and pulse after cutaneous stimulation were $37.03+0.60$ for temperature and $100.42+30.07$ for pulse respectively, while regarding to interactive distrac- tion group it was found that $37.05+.52$ for temperature $98.98+26.05$ for pulse. Statistical significance difference was found regarding Diastolic blood pressure $(P=.011)$. The mean of $\mathrm{O}_{2}$ saturation was $96.30+2.67$ and $96.88+$ 2.84 for the cutaneous stimulation and interactive distraction group after vein-puncture respectively.

Table 7: Comparison between cutaneous stimulation group and interactive distraction group according to vital signs and $\mathrm{O}_{2}$ saturation after vein-puncture

\begin{tabular}{|c|c|c|c|c|c|c|}
\hline \multirow{2}{*}{ Items } & \multicolumn{2}{|c|}{ Cutaneous stimulation } & \multicolumn{2}{|c|}{ Interactive distraction } & \multirow{2}{*}{$t$ test } & \multirow{2}{*}{$P$ value } \\
\hline & Mean & SD. & Mean & SD. & & \\
\hline Temperature & 37.03 & .60 & 37.05 & .52 & .158 & .875 \\
\hline Pulse & 100.42 & 30.07 & 98.98 & 26.05 & .256 & .799 \\
\hline Respiration & 30.72 & 11.56 & 29.20 & 5.42 & .841 & .402 \\
\hline Systolic blood pressure & 107.08 & 10.94 & 105.76 & 16.86 & .464 & .643 \\
\hline Diastolic blood pressure & 67.90 & 10.77 & 62.88 & 8.48 & 12.58 & $.011^{*}$ \\
\hline Oxygen Saturation. & 96.30 & 2.67 & 96.88 & 2.84 & 1.051 & .296 \\
\hline
\end{tabular}

*Significant at $\leq .05$

Correlation between children socio-demographic data and pain scales in both interactive distraction group and cutaneous stimulation group was evident in Table 8 . This table was clarified that there was found statistical significant difference between cutaneous stimulation and interactive dis-

Published by Sciedu Press traction regarding age and number of vein punctures trials at $(<.05)$. There is no found statistical significant difference between cutaneous stimulation and interactive distraction stimulation and interactive distraction regarding to gender and number of past hospitalization. 
Table 8: Correlation Between Children Socio-demographic Data and Pain Scales in both Interactive Distraction Group and Cutaneous Stimulation Group

\begin{tabular}{|c|c|c|c|c|c|c|c|c|}
\hline \multirow{3}{*}{$\begin{array}{l}\text { Socio-demographic } \\
\text { characteristics }\end{array}$} & \multicolumn{4}{|c|}{ Cutaneous stimulation } & \multicolumn{4}{|c|}{ Interactive distraction } \\
\hline & \multicolumn{2}{|c|}{$\begin{array}{l}\text { Visual } \\
\text { analogue scale }\end{array}$} & \multicolumn{2}{|c|}{$\begin{array}{l}\text { Wong-baker faces } \\
\text { pain rating scale }\end{array}$} & \multicolumn{2}{|c|}{$\begin{array}{l}\text { Visual } \\
\text { analogue scale }\end{array}$} & \multicolumn{2}{|c|}{$\begin{array}{l}\text { Wong-baker faces } \\
\text { pain rating scale }\end{array}$} \\
\hline & $r$ & $\boldsymbol{P}$ & $r$ & $\boldsymbol{P}$ & $r$ & $\boldsymbol{P}$ & $r$ & $P$ \\
\hline Age & .135 & .174 & .033 & .409 & -.363 & $.005^{*}$ & -.456 & $.000 *$ \\
\hline Gender & .103 & .238 & .066 & .324 & .113 & .217 & .033 & .411 \\
\hline Number of past hospitalizations & .115 & .213 & .118 & .207 & .058 & .345 & .188 & .095 \\
\hline Number of vein punctures trials & .009 & .479 & .055 & .369 & .262 & .051 & .381 & $.008 *$ \\
\hline
\end{tabular}

*Significant at $\leq .001 ; r=$ correlation test $\& P$ value shows significance at $\leq .001$.

\section{Discussion}

Painful medical procedures are the major sources of distress among children, the procedure-related pain can be worse than that of the illness itself. Pain is considered by the American Pain Society as the fifth vital signs. Age appropriate pain scale was used in the current study. WongBaker Faces pain scale and visual analogue scale were most widely used for this age group, Berman ${ }^{[1]}$ Nurses who perform painful procedures to children should use pain assessment tools and pain management strategies when caring for children as well as adult Sng Q. ${ }^{[4]}$ The most painful and frequently performed invasive procedures by nurses is veinpuncture. It can be classified as a minor invasive procedure but for children it is accompanied by pain, fear and anxiety. For this reason, effort should be made to assess, manage acute pain, improve children outcomes, and shorten hospital stays. Huang ${ }^{[12]}$ Interactive distraction and cutaneous stimulation are non-pharmacological methods utilized by the researchers in this study to decrease pain among children. The current study was conducted to examine the effectiveness of the interactive distraction versus cutaneous stimulation for venipuncture pain relief in school age children. McCaffery, ${ }^{[19]}$ and Willis. ${ }^{[20]}$

The findings of this study found that three quarters of the cutaneous stimulation group and half of the interactive distraction group were admitted to the hospital because of medical problems. Equal percent of one quarter of the interactive distraction group was admitted because of surgical or emergency problems. These results are incongruent with the study held in 2010, who found that, more than three quarters of the children admission to hospital were caused by medical diagnosis. He reported diseases of the respiratory system accounted for nearly $40 \%$ of discharges, diseases of the digestive system, has the highest rate with $37.7 \%$ hospitalizations per 10,000 children in 2009 , also dropped from 44.5 per $10,000 .^{[20]}$

This current study revealed that, nearly two thirds of the children exposed to painful procedures during hospitalization. Slightly more than one third of them had previous vein-puncture 2-3 times while, slightly more than one tenth of them had more than 5 times vein-punctures. The current findings may be due to, that vein-puncture is a routine procedure for children. It is done because of blood sampling, giving medication and so on. This finding supported with the results of Biermeier ${ }^{[14]}$ who found that, nearly all participants in his study had undergone 6 or more previous venous port accesses or vein-punctures. Another study conducted by French ${ }^{[18]}$ stated that insertion of peripheral intravenous devices is one of the most painful and frequently performed invasive procedures during hospitalization and the major cause for pain. Therefore, many children do indeed fear the "needle shot for vein puncture". This can be manifested by the child's distress and increase pain.

Overall in the present study, interactive distraction technique had a most effective pain relieve strategy more than cutaneous stimulation technique. There was statistical significant difference regarding both techniques, and both techniques were effective in relieving pain. These results were supported by the results of Biermeier ${ }^{[14]}$ who concluded that, distraction was commonly effective and consistently reduced distress but produced mixed results in lowering pain. Kleiber ${ }^{[16]}$ also support these results. It has been suggested that distraction may have more observable effects on the sensory and affective components of pain than on the pain intensity reports Piira. ${ }^{[2]}$ These findings support current evidence that distraction strategies reduce pain perception. ${ }^{[23-25]}$

It was observed that distraction is the most frequent intervention to guide children's attention away from the painful stimuli and reduce pain and anxiety. However, our results were similar with study for Bagheriyan ${ }^{[26]}$ concluded that distraction is an effective, non-expensive, and easy-to access technique to control and reduce pain in children during IV catheter placement and effective in reducing the behavioral responses of pain in children who underwent IV catheter placement.

The Visual Analogue Scale in the current study generally revealed differences in children's reaction to vein-puncture. The most effective method was the distraction technique which was found to have statistical different properties com- 
pared to the Cutaneous Stimulation technique. These findings are in agreement with the study of McClellan ${ }^{[27]}$ who found that, child-report, parent-report, and observational measures all showed significant changes from pre- to postvein puncture. These findings also parallel the results of others who have reported that the Observation Scale of Behavioral Distress is sensitive to detecting changes in behavioral distress using cognitive-behavioral interventions to manage pain. Pringle, ${ }^{[28]}$ Dahlquist, ${ }^{[29]}$ Ahn \& Yan ${ }^{[30]}$ and Willis ${ }^{[20]}$ all report that parent distress ratings of their children were similar to distress ratings by the nurse.

The findings of this study regarding vital signs and $\mathrm{O}_{2}$ saturation assessment before and after vein- puncture revealed that, there were differences in the mean of temperature, pulse, respiration, blood pressure \& $\mathrm{O}_{2}$ Sat. between the two groups in general with a most lower means in interactive distraction group as compared to cutaneous stimulation group. The statistical significant difference was found in the mean of blood pressure between the two groups. These findings is inconsistent with the study of McClellan ${ }^{[27]}$ who were reported that no significant differences between baseline and pre-procedural heart rate and Heart rate did not show the expected increase from pre- to post-vein puncture. Linhares $^{[31]}$ also found no statistical significance regarding heart rate in his study.

Finally, this study demonstrates that non- pharmacological methods include interactive distraction and cutaneous stimulation have been found to be an effective, safe and simple adjunctive methods for the control and relief of children pain prior to venipuncture.

\section{Conclusion}

The present study concludes that; non pharmacological techniques have a positive pain relief effect on children's pain during vein-puncture. Interactive distraction technique had a positive pain relive effect and was better than cutaneous stimulation in relieving children's pain during veinpuncture. There is significant difference between the effect of cutaneous stimulation and interactive distraction techniques on children's pain during vein-puncture. Management of children's pain during vein-puncture using interactive distraction versus cutaneous stimulation techniques remains a major challenge for the nurses in hospitals because it needs more training and experience.

\section{Recommendations}

The following recommendations are suggested

(1) Application of non-pharmacological pain management in hospitals as a routine and daily care.

(2) Implement an educational program for the nurses on how to assess and manage children's pain during painful procedure.

(3) Future studies needed to evaluate the effectiveness of other non-pharmacological management techniques.

(4) Application of the study in a large sample size, and on other age group.

(5) Nurses need to expand their knowledge, increase their skills regarding pediatric pain by application of nonpharmacologic interventions.

\section{Acknowledgements}

I would like to express great appreciation for all medical and nursing staff who contributed actually or morally in the performance of this study.

\section{Conflicts of Interest Disclosure}

The authors declare that there is no conflict of interest statement.

\section{References}

[1] Berman A, Snyder S, Kozier B, et al. Fundamentals of Nursing: Concepts, Process, and Practice. 8th ed., Julie Levin Alexander: Prentice Hall Company. 2008; 1187-1230.

[2] Black J, Hawks J, keene A. Medical-Surgical Nursing Clinical Management for Positive Outcomes. 6th ed., Simon Company. 2005; 461-528.

[3] American Pain Society: Pediatric Chronic Pain: A Position Statement from the American Pain Society. 2003.

[4] Sng QW, Taylor B, Liam JL, et al. Postoperative Pain Management Experiences Among School-Aged Children: A Qualitative Study. J Clin Nurs. 2013; 22(7-8): 958-68. PMid:23311588 http: //dx.doi.org/10.1111/jocn.12052

[5] Royal Australasian college of physicians. Management of Procedure Related Pain in Children and Adolescents. Journal of Pediatrics and Child Health. 2006; 42: 51-529.

Published by Sciedu Press
[6] Stinson J. Assessing Younger School-Aged Children Age Five to Eight, 2009. Available from: http: //www . aboutkidshealth.ca/En/ResourceCentres/Pa in/PainAssessment/PainAssessmentbyAge/Pages/Assess ing-Younger-School-aged-Children-age-5-to-8. aspx .

[7] Gilboy S, Hollywood E. Helping To Alleviate Pain for Children Having Venipuncture. Pediatrics Nursing. 2009; 21(8): 1419. PMid:19886563 http://dx.doi.org/10.7748/paed2009. 10.21.8.14.c7287

[8] Wong DL, Hockenberry MJ. Nursing Care of Infant and Children. 7 th ed. St Louis, Missouri: Mosby, 2003.

[9] Das DA, Grimmer KA, Sparnon AL, et al. The Efficacy of Playing a Virtual Reality Game in Modulating Pain for Children With Acute Burn Injuries: A randomized controlled trial. BMC Pediatrics. 2005; 5(1). PMid:15745448 http://dx.doi.org/10.1186/1471-243 1-5-1

[10] Crisp J, Taylor C. Potter and Perry's Fundamental of Nursing. 2nd ed. Sydney: Elsevier Australia, 2005. 
[11] Cohen LL, Lemanel K, Blount RL, et al. Evidence-Based Assessment Of Pediatric pain. J. Ped. Psychol. 2008; 33(9): 939955. PMid:18024983 http://dx.doi.org/10.1093/jpepsy/ jsm103

[12] Huang C, Tung W, Kuo L, et al. Comparison Of Pain Responses Of Premature Infants To The Heel stick Between Containment And Swaddling. Journal of Nursing Research. 2004; 12(1): 3140. PMid:15136961 http://dx.doi.org/10.1097/01. JNR. 00 $00387486.78685 . c 5$

[13] Taylor EM, Boyer K, Campbell FA. Pain In Hospitalized Children: A Prospective Cross-Sectional Survey Of Pain Prevalence, Intensity, Assessment And Management In A Canadian Pediatric Teaching Hospital. Pain Research Management. 2008; 13: 25-32. PMid:18301813

[14] Biermeier A, Sjoberg I. Effects of Distraction on Pain, Fear, and Distress. During Venous Port Access and Venipuncture in Children and Adolescents with Cancer. Journal of Pediatric Oncology Nursing. 2007; 24(1): 8-19. PMid:17185397 http://dx.doi.org/1 $0.1177 / 1043454206296018$

[15] Kharasch S. Pain Treatment: opportunities and challenges. Archives of Pediatric and Archives Medicine. 2003; 157(11): 10541056. PMid:14609892 http://dx.doi.org/10.1001/archped i. 157.11 .1054

[16] Kleiber C, Harper DC. Effects Of Distraction On Children's Pain And Distress During Medical Procedures: A Meta-Analysis. Nursing Research. 1999; 48: 44-49. PMid:10029401 http://dx.doi .org/10.1097/00006199-199901000-00007

[17] Rogers TL, Lynne SC. The use of EMLA cream to decrease venipuncture pain in children. Journal of Pediatric Nursing. 2004; 19(1): 33-39. PMid:14963868 http://dx.doi.org/10.1016/j .pedn.2003.09.005

[18] French MG. Blowing Away Shot Pain: A Technique For Pain Management During Immunization. Journal of Pediatrics. 2003 June; 6. Available from: http://www.ncbi.nlm.nih.gov/pudmed. Accessed July 28, 2012.

[19] Mc Caffery M, Arnstein P. The Debate Over Placebos in Pain Management. American Journal of Nursing. 2006; 106(2): 62-65. Available from: http://www.livestrong.com/article/204918-v enipuncture-tips. http://dx.doi.org/10.1097/0000044 6-200602000-00026

[20] Willis MHW, Merkel SI, Voepel-Lewis T, et al. FLACC Behavioral Pain Assessment Scale: A Comparison With A Child's Self-Report. Pediatr Nurs. 2003; 29: 195-8. PMid:12836995
[21] Ferrer AP, Sucupira AC, Grisi SJ. Causes Of Hospitalization Among Children Ages Zero To Nine Years Old In The City Of São Paulo, Brazil. Clinics (Sao Paulo). 2010; 65(1): 35-44.

[22] Piira T, Hayes B, Goodenough B. Distraction Methods in the Management of Children's Pain: An Approach Based on Evidence or Intuition? The Suffering Child. 2005; 1: 1-10.

[23] Powers SW. Empirically Supported Treatments In Pediatric Psychology: Procedure-Related Pain. Journal of Pediatric Psychology. 1999; 24: 131-145. PMid:10361392 http://dx.doi.org/10.1093/jpepsy/24.2.131

[24] Chen E, Joseph M, Zeltzer LK. Behavioral and cognitive interventions in the treatment of pain in children. Pediatric Clinics of North America. 2000; 47: 513-525. http://dx.doi.org/10.1016/S 0031-3955 (05) 70223-6

[25] Kump, Brown RT. Painful procedures in pediatric cancer: A component of interventions. Clinical Psychological Review. 2002; 22: 753786. http://dx.doi.org/10.1016/S0272-7358(02)00105-8

[26] Bagheriyan S, Borhani F, Abbaszadeh A. Analgesic Effect of Distraction during Venipuncture in Children With Thalassemia. Iranian Journal of Blood and Cancer. 2012; 1: 9-14.

[27] McClellan CB, Jeffrey C, et al. Criterion And Convergent Validity For Four Measures Of Pain In A Pediatric Sickle Cell Disease Population. Clin J Pain. 2009; 25(2): 146-152. PMid:19333161 http://dx.doi.org/10.1097/AJP.0b013e3181839ac4

[28] Pringle B, Hilley L, Gelfand K, et al. Decreasing Child Distress During Needle Sticks And Maintaining Treatment Gains Over Time. Journal of Clinical Psychology in Medical Settings. 2001; 8: 119130. 39.

[29] Dahlquist LM, Pendley JS, Landthrip DS, et al. Distraction Intervention For Preschoolers Undergoing Intramuscular Injections And Subcutaneous Port Access. Health Psychology. 2002; 21: 94-99. PMid:11846350 http://dx.doi.org/10.1037/0278-6133.21 .1 .94

[30] Ahn Y, Jun Y. Measurement Of Pain-Like Response To Various NICU Stimulants For High-Risk Infants. Early Hum Dev. 2007; 83: 255-62. PMid:16854537 http://dx.doi.org/10.1016/j.e arlhumdev. 2006.05.022

[31] Linhares D, Martinez, Carlotti CP, et al. Pediatric Pain: Prevalence, Assessment, and Management in a Teaching Hospital. Braz J Medical logical Research. 2012; 45(12): 1287-1294. 